\title{
AC 2010-376: STUDENTS IMPROVING: IDENTIFYING FACTORS THAT SEEM TO MATTER
}

\section{Elizabeth Otto, Stanford University}

Elizabeth Otto is a second year graduate student at Stanford University pursuing a Ph.D. degree in Applied Physics with interests in Biophysics and Science and Engineering Education. She received her B.S. degree from the University of Michigan at Ann Arbor in 2008 in Physics and Mathematical Sciences and expects to receive an M.S. degree from Stanford University in Applied Physics in 2010.

\section{Helen Chen, Stanford University}

Helen L. Chen is a Research Scientist at the Stanford Center for Innovations in Learning and Research Associate in the Center for the Advancement of Engineering Education. Her current research interests focus on the application of ePortfolio pedagogy and practices to facilitate teaching, learning, and assessment for students, faculty, and institutions. She is also interested in the exploration of the affordances and scalability of these kinds of social software tools and their implications for the design and evaluation of innovative learning spaces to support formal and informal learning.

\section{Sheri Sheppard, Stanford University}

Sheri D. Sheppard is the Burton J. and Deedee McMurtry University Fellow in Undergraduate Education, Associate Vice Provost for Graduate Education, and Professor of Mechanical Engineering at Stanford University. She is also a consulting senior scholar at the Carnegie Foundation, having directed the Preparations for the Professions Program (PPP) engineering study, and co-authored the study's report Educating Engineers: Designing for the Future of the Field (2008). Before coming to Stanford University, she held several positions in the automotive industry, including senior research engineer at Ford Motor Company's Scientific Research Lab. She earned a Ph.D. at the University of Michigan. 


\title{
STUDENTS IMPROVING: IDENTIFYING FACTORS THAT SEEM TO MATTER
}

\begin{abstract}
In this paper we explore engineering student gains in confidence in professional and interpersonal skills and intrinsic psychological motivation to study engineering. These two factors were selected because they have been shown in other work from the Academic Pathways Study (APS) sponsored by the Center for the Advancement of Engineering Education (CAEE) to be directly related to post-graduation plans and to several dimensions of the undergraduate experience. We focus on students with positive confidence and/or motivation gains during their first two years of college, and show that these students are distinct from those with negative or no gains in terms of persistence in the engineering profession, confidence in math and science skills and perceived importance of math and science skills to engineering. Interviews of these "positive gain" students and their "negative gain" peers suggest differences in their attitudes toward and experiences with math and science.
\end{abstract}

\section{INTRODUCTION}

Recent findings from the Academic Pathways Study (APS) have shown that among the factors that predict the post-graduation plans of seniors - plans to pursue engineering or non-engineering work and plans to attend engineering or non-engineering graduate school—are students' confidence in their professional and interpersonal skills and their level of intrinsic psychological motivation to study engineering. These two variables, when taken in combination, also distinguish the overall college experience of students. Sheppard et al. (2010) delineated findings showing that seniors who are both highly confident and motivated are highly involved in college; they are more involved in extracurricular activities including research, co-op, internship and nonengineering activities, report higher gains in knowledge, and interact more with faculty than students who are at the bottom end of confidence and motivation ${ }^{\mathrm{i}}$. Those with high motivation/low confidence and low motivation/high confidence report levels of involvement intermediate to students at the two extremes. 
It may seem surprising to find both confidence and motivation associated with predicting postgraduate plans and shaping the college experience. But confidence relates to the experiences one seeks out (which may in turn build confidence), and these experiences in turn are likely to affect future plans and opportunities. Employers are increasingly calling for well-developed professional skills in engineering hires and ABET Inc. has established a set of six professional skill outcomes that engineering baccalaureate graduates should possess ${ }^{i i, i i i}$. Motivation, what drives one to pursue something, also influences how one chooses to spend time both in school and in career planning.

In this study, we test the explanatory power of framing undergraduate engineering populations according to measures of their intrinsic psychological motivation and professional and interpersonal confidence. We use scores of these and other variables from a longitudinal data set collected from a cohort of 38 students from a Suburban Private University who participated in the Academic Pathways Study between 2003 and $2007^{\text {iv }}$. We identify changes in confidence and motivation scores over time (using survey data from the Persistence in Engineering (PIE) survey that was completed seven times during the students' four years of involvement in the APS), and use scores on other variables and interview data to further investigate students' experiences while these changes were occurring. The interview data come from a set of structured and ethnographic interviews that the students participated in during the same time period that were also part of the APS.

We identify a group of students who experienced positive gains in these confidence and motivation measures during the first two years of college (a particularly formative period in a student's development of identity with and commitment to engineering). In order to answer the question, "what college experiences might be promoting/prompting/fostering these gains?" we consider how these "positive gain" students compare with their peers with negative or no gains in confidence in their professional and interpersonal skills and their level of intrinsic psychological motivation to study engineering.

\section{BACKGROUND}

To organize our work, we used an approach based on measures of confidence and motivation that is designed to shed light on the relationship between the college experience and post- 
graduation plans developed as part of the Academic Pathways of People Learning Engineering Survey (APPLES) ${ }^{1}$, a sub-study of the APS. This "Quadrant Analysis" framework classifies students into four groups, or "quadrants," according to whether their scores on these two variables are above or below the population mean. The four quadrants are defined as the high intrinsic motivation and high professional and interpersonal confidence quadrant, the low motivation and low confidence quadrant, the high motivation and low confidence quadrant and the low motivation and high confidence quadrant. In the APPLE study, the Quadrant Analysis was applied to survey data from engineering seniors at 21 institutions nationwide. Student characteristics and activities such as extracurricular involvement and interaction with faculty as well as post-graduation plans were found to differ significantly among the four quadrants. The result was a robust framework for mapping the "landscape" of engineering students.

This paper builds on prior research and begins with a review of some important methodological "features" of that work, followed by descriptions of key ideas, definitions and findings.

\section{Definition: Intrinsic Psychological Motivation Variable}

The intrinsic psychological motivation variable measures students' inherent interest in and enjoyment of engineering work. When intrinsically motivated, students engage in behaviors for the fun and challenge entailed rather than in response to external pressures or in order to reap rewards. In contrast, extrinsic motivation refers to doing something because it leads to a separable outcome or reward, such as money or a grade. These external rewards provide satisfaction or enjoyment that may be unrelated to the task itself.

Self-determination theory (SDT) suggests that people act based on intrinsic and extrinsic motivations to fulfill basic human needs for autonomy, competence and relatedness (Ryan and Deci, 2000) ${ }^{\mathrm{v}}$. The quality of the experience, performance, and learning may vary considerably depending upon the type of motivation that stimulates behavior. 
In the APPLE/PIE surveys, the intrinsic psychological motivation variable is a modified version of the intrinsic motivation subscale of the Situational Motivation Scale (SIMS) (Guay, Vallerand, and Blanchard, 2000) ${ }^{\mathrm{vi}}$ and is comprised of three survey items (questions) ${ }^{1}$ :

a) I feel good when I am doing engineering activities

b) Majoring in engineering is fun

c) I think engineering is interesting

Students were asked to indicate the extent to which they agreed that each of the items was a reason why they were studying engineering, and they had the option to respond: "strongly disagree," "moderately disagree," “disagree," "unsure," "agree," "moderately agree," and "strongly agree." The Cronbach's alpha statistic measures the internal consistency of the individual items that make up a variable and represent the extent to which the items can be considered to measure the same variable. The Cronbach's alpha value for this variable was 0.75 .

\section{Definition: Confidence in Professional and Interpersonal Skills Variable}

The confidence in professional and interpersonal skills variable was intended to assess students' self-confidence in their business, communication and teamwork proficiencies. Confidence variables were included in the PIE surveys to explore the relationship between confidence and persistence in engineering as posited in literature. For example, Seymour and Hewitt identified "feeling discouraged/losing confidence due to low grades in early years" as a persistence factor in their influential qualitative study of persistence in science and engineering education, which included interviews of over 300 juniors and seniors at 7 institutions ${ }^{\text {vii }}$.

The professional and interpersonal confidence variable as defined in this work is composed of the following items ${ }^{2}$ :

\footnotetext{
${ }^{1}$ The wording of the items given here is the same as that used in the PIE surveys. The same three items made up the variable in the APPLE survey, but slightly different wording was used: the word "activities" was removed from a) and the words "majoring in" in b) were replaced with "I think". The quoted Cronbach's alpha value was based on responses to the APPLE survey.

${ }^{2}$ In the iterations of PIE after the second survey and in the APPLE survey, the additional item "Ability to perform in teams" was added to this variable. For consistency in this work, we defined the variable as being composed of
} 

a) Social self confidence
b) Leadership ability
c) Public speaking ability
d) Communication skills
e) Business ability

The students were asked to rate themselves on the above traits as compared to their peers on a scale of "lowest 10\%," "below average," "average," "above average," and "highest 10\%." The Cronbach's alpha value for this variable was 0.82 .

Within each variable, each individual item was given equal weight when calculating the variable score. The scores for both the confidence and motivation variables were normalized on a scale of 0 to 1 .

\section{Definition: Quadrant Analysis}

Figure 1. Quadrant Analysis Description of the APPLES Senior Population [3]

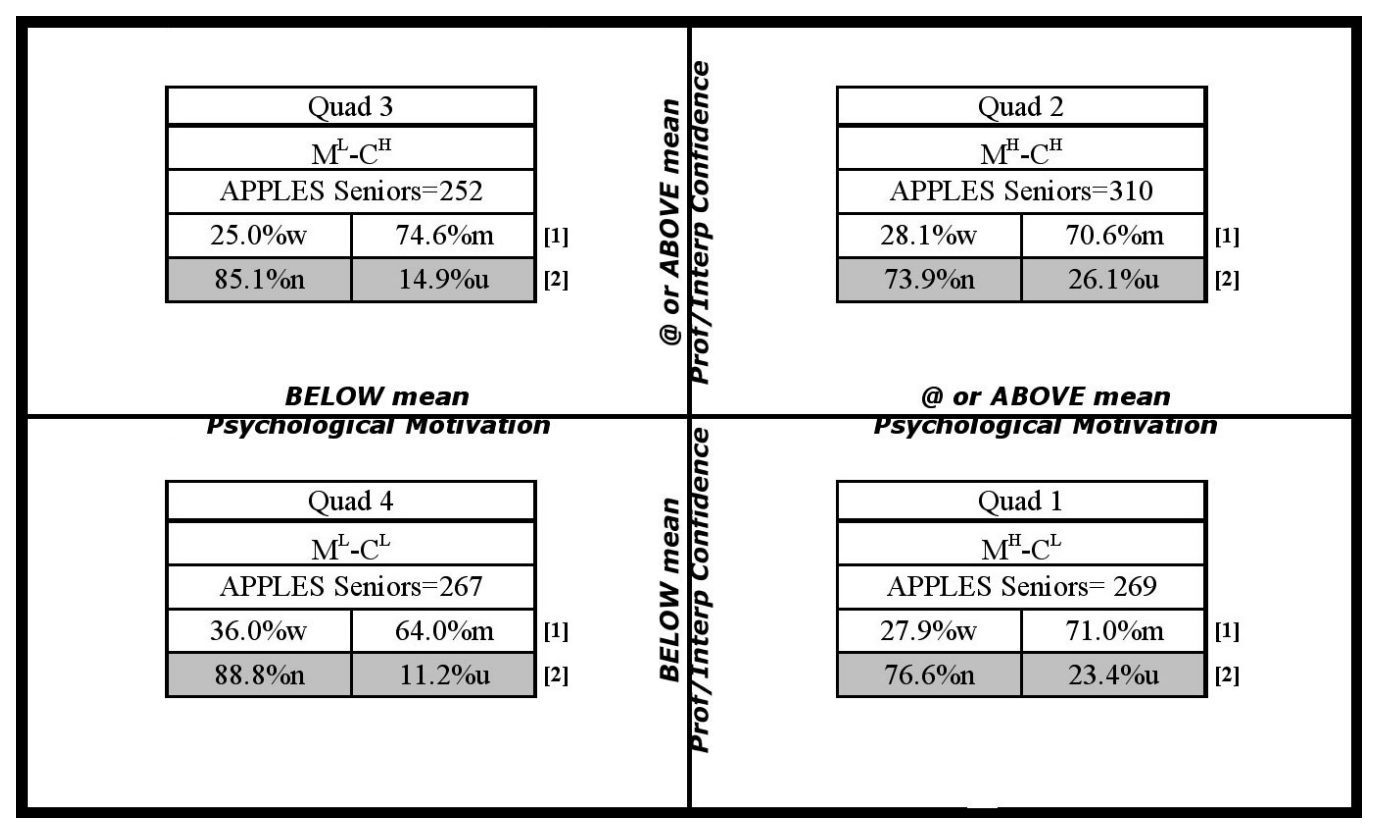

Figure Notes:

[1] w: women, m: men

only five items, since we wanted to use data from the first and second surveys. The quoted Cronbach's alpha statistic comes from the APPLES data. 
[2] n: non-Underrepresented Minority (URM), u: URM

[3] M: Intrinsic psychological motivation, C: Confidence in professional and interpersonal skills, L: Low, H: High

In applying the Quadrant Analysis, we created a scatterplot based on students' measures of intrinsic psychological motivation and professional and interpersonal confidence. We divided the plot into four "quadrants" according to the mean values of the plotted data. Students were classified into one of the four quadrants according to where they fell on this plot: below the motivation mean and above the confidence mean (quadrant 1), above both means (quadrant 2), above the confidence mean and below the motivation mean (quadrant 3), or below both means (quadrant 4). Figure 1 illustrates the definitions of the quadrants. When the APPLES cohort was divided into the four quadrants, the demographic compositions of the four quadrants were comparable, as summarized in Figure 1.

In this work, the Quadrant Analysis was used to address whether undergraduate engineering students' levels of confidence and motivation and their resulting quadrant characterization change over time. Students are grouped according to the types of quadrant changes they experience and the range of factors that may contribute to these changes are explored in both quantitative survey responses and qualitative interviews conducted with the students during their first two years of college.

\section{METHODOLOGY}

\section{Summary of Steps:}

1) Calculate motivation and confidence scores for 38 students at two points during their first two years;

2) Identify students who experienced "positive gains", "no gains" and "negative gains" during their first two years;

3) Compare the responses of the three "positive gain", "no gain", and "negative gain" groups on college experience measures (other PIE study variables); identify distinguishing factors; 
4) Explore qualitative interviews as directed by the distinguishing factors identified in 3); assess what seems important to "positive gain" students.

\section{Description of Datasets:}

This study is based on survey data from the Persistence in Engineering Study (PIE), one part of the Academic Pathways Study (APS). The PIE survey was administered longitudinally between 2003 and 2007 to a cohort of forty students at each the four CAEE institutions, from their matriculation to the end of their fourth year of college. All of the students who participated in the study were either completing an engineering program or intending to major in engineering. These analyses focus only on students from this cohort who attended a Suburban Private University. We further limit the subjects to the 38 individuals who answered all of the survey items necessary to calculate the intrinsic psychological motivation and professional and interpersonal confidence variables. We only consider data from these students' first two years in college, in order to focus on changes taking place during this critical formative period. Further details on the development, administration and results of the PIE sub-study are documented elsewhere $^{4, \text { viii }}$.

The quantitative comparison of the three groups is complemented by a qualitative investigation focused on the "positive gain" and "negative gain" groups. By way of background, during each year of their participation in the PIE study, subsets of the cohort participated in ethnographic and structured interviews. In the structured interviews students responded to a standard set of questions, and in the ethnographic interviews students received prompts and encouragement to talk freely about their experiences. Here we reference data from both types of interviews. Comments such as "um," "you know," "I mean," and other words and phrases that generally obscure or detract from the clarity and meaning of the quotes have been removed.

\section{Details of Methodology:}

Using the Quadrant Analysis approach, we defined four quadrants based on the intrinsic psychological motivation and professional and interpersonal confidence scores from the $2^{\text {nd }}$ and $4^{\text {th }}$ administrations of the PIE survey, conducted during April 2004 (spring of the students' 1st 
year) and April 2005 (spring of the students' 2nd year). The means for these two datasets were calculated separately, and the quadrants were defined independently at each of the two time points. The means and standard deviations are given in Table 1.

Table 1. Mean and Standard Deviations of Variable Scores in Years 1 and 2

\begin{tabular}{|c|c|c|}
\hline & $\begin{array}{c}\text { Intrinsic Psychological } \\
\text { Motivation [scale of 0-1] }\end{array}$ & $\begin{array}{c}\text { Professional and Interpersonal } \\
\text { Confidence [scale of 0-1] }\end{array}$ \\
\hline Year 1 (Spring 2004) & $0.761 \pm 0.170$ & $0.678 \pm 0.162$ \\
\hline Year 2 (Spring 2005) & $0.719 \pm 0.176$ & $0.676 \pm 0.158$ \\
\hline
\end{tabular}

We observed that some students remained in the same quadrant between their freshman and sophomore years, while others transitioned between quadrants. Since we knew that at least for the APPLES dataset, a student's quadrant characterization potentially suggests a great deal about their approach to college, we wondered what factors might stimulate a transition between quadrants. In particular, we became interested in students who made transitions between quadrants due to positive increases in one or both of the variables. In the long run, we hope that a better understanding of the experiences of these students might inform possible changes to the engineering learning environment and curriculum.

In order to differentiate the students who experienced only "positive gains," we divided the study population into three groups: the No Transition Group, the Positive Transition Group and the Other Transition Group. Students in the No Transition Group stayed in the same quadrant between the two time points. Students in the Positive Transition Group transitioned between quadrants only in the direction of increase in one or both of the variables: for example, if students moved from Quadrant 1 to Quadrant 2 because of an increase in professional and interpersonal confidence. Students in the Other Transition Group made at least one transition between quadrants in a decreasing direction of one of the variables, e.g., from Quadrant 2 to Quadrant 3 because of decreasing intrinsic psychological motivation. To clarify, students who made "diagonal" transitions were classified as Other Transition students unless they moved from Quadrant 4 to Quadrant 2 (only positive transitions). If a student moved in the net decreasing 
direction of at least one variable, he or she was considered an Other Transition student. We made this distinction in order to fully isolate the experience of making a positive transition between quadrants.

Table 2. Student Quadrant Placements and Transition Groups

Year 1 (Spring 2004)

\begin{tabular}{|c|c|c|c|c|c|}
\hline & & Quad 1 & Quad 2 & Quad 3 & Quad 4 \\
\hline \multirow{4}{*}{$\begin{array}{c}\text { Year } 2 \\
\text { (Spring 2005) }\end{array}$} & Quad 1 & 5 & 1 & 0 & 5 \\
\hline & Quad 2 & 5 & 5 & 2 & 0 \\
\hline & Quad 3 & 1 & 2 & 7 & 0 \\
\hline & Quad 4 & 1 & 0 & 1 & 3 \\
\hline
\end{tabular}

\begin{tabular}{|c|c|}
$\begin{array}{c}\text { Group Totals and } \\
\text { Color Legend }\end{array}$ \\
$\mathrm{NT}=$ & 20 \\
$\mathrm{PT}=$ & 12 \\
$\mathrm{OT}=$ & 6 \\
\hline
\end{tabular}


Figure 2. Quadrant Analysis Description of the Study Population During Spring of $2^{\text {nd }}$ Year

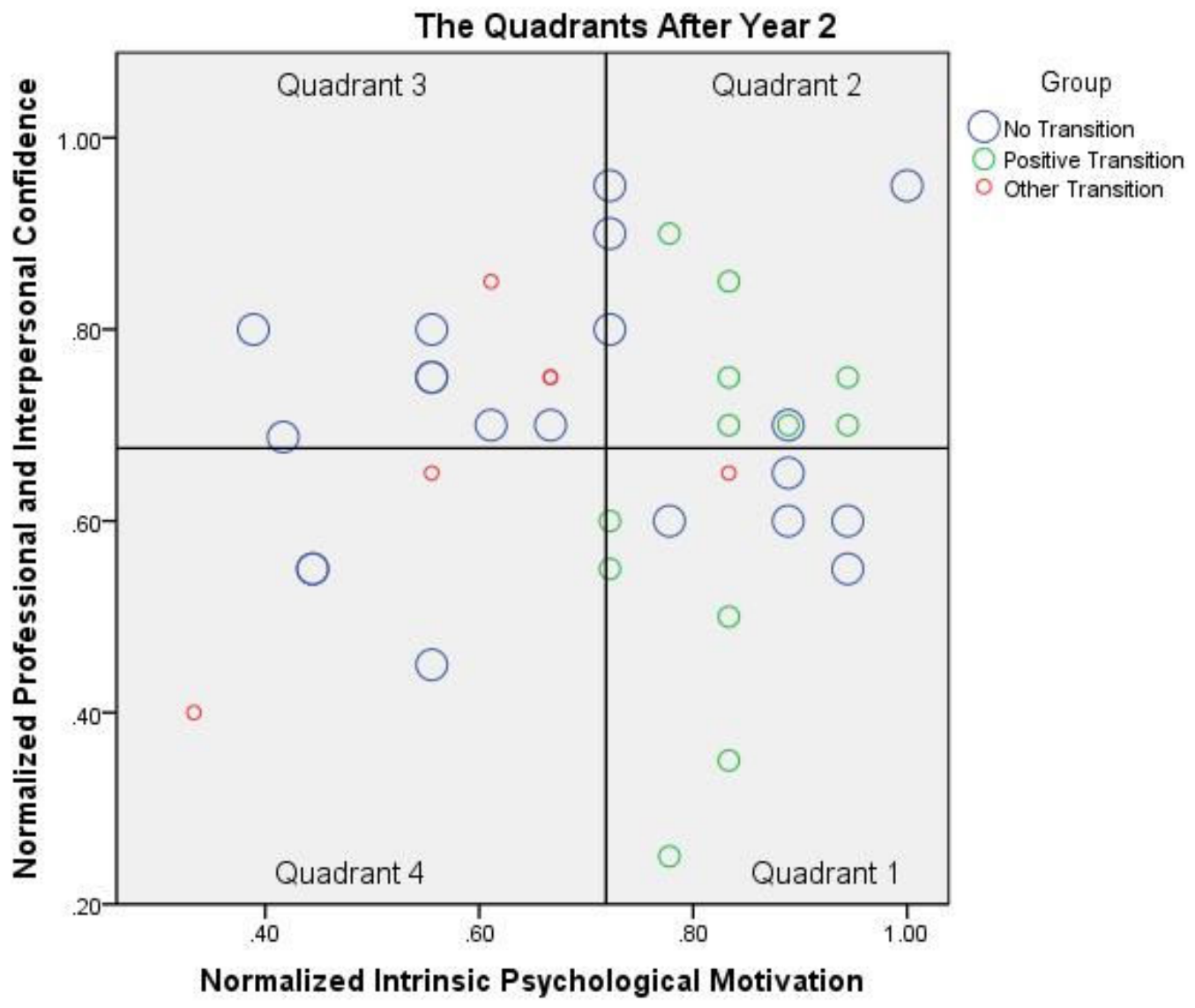

Table 2 tallies the number of students who experienced each type of quadrant transition, categorized as No Transition (NT), Positive Transition (PT) or Other Transition (OT). In the end, there were 20 students in the No Transition Group, 12 students in the Positive Transition Group, and 6 students in the Other Transition Group. These same data are displayed in Figure 2, based on the 2005 position of each student, with each circle representing a student in the study population and their transition group assignment.

Next we explored the similarities and differences among the three groups based on their demographics, future plans, and scores on the PIE variables related to the college experience. Ttests and analysis of variance (ANOVA) tests were used to identify statistically significant differences between group mean scores. These analyses are presented in the following section.

RESUlts

Demographic Characteristics of the Groups: 
We explored the statistical similarities and differences between the three groups using PIE survey data. Table 3 summarizes the gender and underrepresented minority status (URM) demographics of the three groups and Table 4 shows the findings regarding "academic" and "professional persistence." In the APS, an "academic persister" is defined as a student who completes an engineering undergraduate degree as documented in their academic transcript. A "non-persister" either completed a non-engineering degree or stated in an interview that he or she would not be pursuing engineering. In this work, we classify an individual as a "professional persister" if he or she answered "definitely yes" or "probably yes" to the question, "Do you intend to practice, conduct research in, or teach engineering for at least 3 years after graduation?" in the PIE survey administered during the spring of their senior year.

Binomial tests were used to test the likelihood that the proportion of, for example, males in the Positive Transition Group is different from the expected proportion of males in all three subgroups combined. The p-values from the binomial tests are given below the proportions for each item in Tables 3 and 4. As Table 3 shows, the groups are not statistically different with regard to gender, though we do note that the Other Transition Group had the lowest percentage of females (17\% female) while the No Transition Group had the highest ( $40 \%$ female). The percentages of URM students in the three groups were also roughly equal ${ }^{3}$.

We found that the Positive Transition Group had the highest percentage of academic persisters and professional persisters. In fact, the proportion of professional persisters in the PT subgroup was significantly higher than the proportion in the three groups as a whole, at the $\mathrm{p}<.05$ level (see Table 4).

Table 3. Demographic Comparisons of the Three Transition Groups

\section{Demographics}

\footnotetext{
${ }^{3}$ URMs are students who come from Native Hawaiian or Pacific Islander, Black/African-American, Hispanic or Latino/a, Native American ethnic backgrounds, or any combination of the four. Non-URMs are students of Asian or Asian American, White, or White and Asian or Asian American ethnicities. Students of mixed ethnicities that are combinations of URM and non-URM ethnicities are considered neither URM nor non-URM. Ethnicity was determined from PIE 1 survey responses and interview data when the student responded "Other" in the survey.
} 


\begin{tabular}{|c|c|c|c|c|c|c|}
\hline & \multicolumn{2}{|c|}{ No Transition Group } & Positive Transition Group & \multicolumn{2}{c|}{$\begin{array}{c}\text { Other Transition } \\
\text { Group }\end{array}$} \\
\hline $\mathrm{N}$ & \multicolumn{2}{|c|}{20} & \multicolumn{2}{c|}{12} & \multicolumn{2}{c|}{6} \\
\hline Gender & $60 \%$ male & $\begin{array}{c}40 \% \\
\text { female }\end{array}$ & $75 \%$ male & $\begin{array}{c}25 \% \\
\text { female }\end{array}$ & $83 \%$ male & $\begin{array}{c}17 \% \\
\text { female }\end{array}$ \\
\hline $\begin{array}{c}\text { Gender } \\
\text { Binomial Test } \\
\text { p-value }\end{array}$ & \multicolumn{2}{|c|}{0.292} & \multicolumn{2}{|c|}{0.432} & & \\
\hline \\
$\begin{array}{c}\text { URM Status } \\
\text { URM }\end{array}$
\end{tabular}

Table 4. Academic and Professional Persistence Comparison of the Three Transition Groups

Persistence Data

\begin{tabular}{|c|c|c|c|c|c|c|}
\hline & \multicolumn{2}{|c|}{ No Transition Group } & \multicolumn{2}{|c|}{ Positive Transition Group } & \multicolumn{2}{|c|}{ Other Transition Group } \\
\hline $\begin{array}{l}\text { Academic } \\
\text { Persistence }\end{array}$ & $\begin{array}{c}65 \% \\
\text { persister }\end{array}$ & $\begin{array}{l}35 \% \text { non- } \\
\text { persister }\end{array}$ & $\begin{array}{c}83 \% \\
\text { persister }\end{array}$ & $\begin{array}{l}17 \% \text { non- } \\
\text { persister }\end{array}$ & $\begin{array}{c}50 \% \\
\text { persister }\end{array}$ & $\begin{array}{l}50 \% \text { non- } \\
\text { persister }\end{array}$ \\
\hline $\begin{array}{c}\text { Academic } \\
\text { Persistence } \\
\text { Binomial Test }^{\text {p-value }}{ }^{\mathrm{d}}\end{array}$ & \multicolumn{2}{|c|}{0.469} & \multicolumn{2}{|c|}{0.208} & \multicolumn{2}{|c|}{0.294} \\
\hline $\begin{array}{c}\text { Professional } \\
\text { Persistence }\end{array}$ & \multicolumn{2}{|c|}{$42 \%$} & \multicolumn{2}{|c|}{$83 \%$} & \multicolumn{2}{|c|}{$33 \%$} \\
\hline $\begin{array}{c}\text { Professional } \\
\text { Persistence } \\
\text { Binomial Test }^{\text {p-value }}{ }^{\mathrm{d}}\end{array}$ & \multicolumn{2}{|c|}{0.209} & \multicolumn{2}{|c|}{$0.036(* \mathrm{p}<.05)$} & \multicolumn{2}{|c|}{0.272} \\
\hline
\end{tabular}

${ }^{4}$ Each binomial test compares one subgroup to the three groups combined.

${ }^{5}$ Percentage of those who responded; one individual in the No Transition Group did not take the senior spring survey. 


\section{Math and Science Confidence Differences of the Groups:}

The PIE survey contains a number of variables related to motivation to study engineering and confidence in key engineering skills, as well as variables on the college experience, as described in Özgür et al. (2009) ${ }^{8}$. On many of these measures the Positive Transition, No Transition, and Other Transition groups were no different. Noteworthy, however, is the relatively high mean for confidence in math and science skills of students in the Positive Transition Group; this mean is consistently higher for students in the Positive Transition Group than for students in the No Transition Group across all four administrations of PIE (though not statistically significant), and significantly higher than that of students in the Other Transition Group in the third and fourth administrations (see Figure 4 and Table 5).

Figure 4. Transition Group Mean Math and Science Confidence Over Time

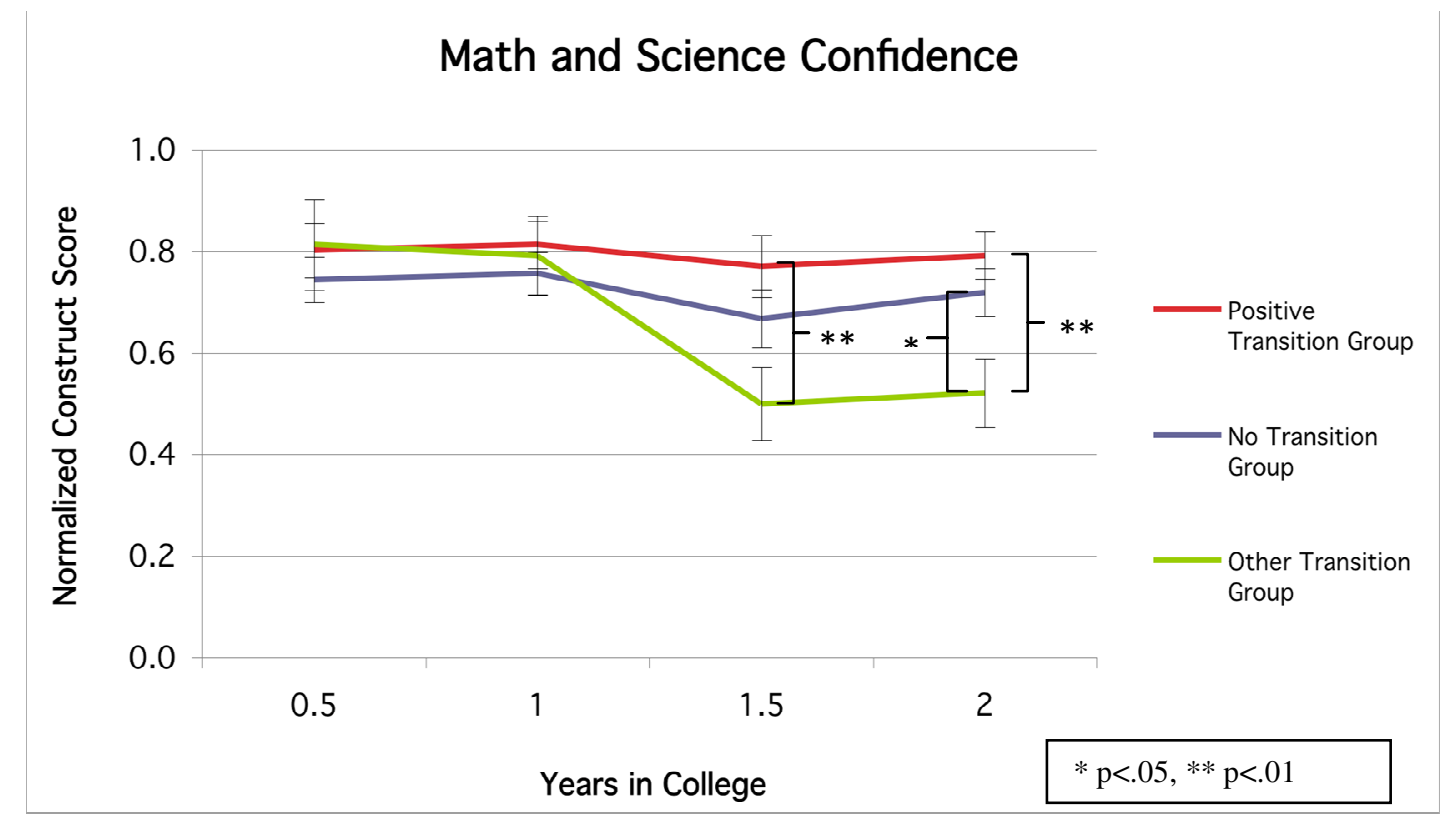


Recalling the high professional persistence of the Positive Transition Group (Table 3), it may be the case that high math and science confidence in their first two years of college helped to bolster their confidence more generally during the college experience, keeping them on track to continue in engineering. Note also the major drop in math/science confidence of the Other Transition Group in their second year of college. Recall that this group had the fewest number of academic and professional persisters (Table 3). It might be that that this early drop in math and science confidence is a precursor to a later decision to move away from engineering.

Table 5. Statistical Significance of Difference in Means Between Transition Groups Over Time

\begin{tabular}{|l|l|l|l|l|}
\hline \multirow{2}{*}{} & \multicolumn{4}{|c|}{ Years in College } \\
\cline { 2 - 5 } & 0.5 & 1.0 & 1.5 & 2.0 \\
\hline $\begin{array}{l}\text { Confidence in } \\
\text { Math and } \\
\text { Science }\end{array}$ & NS & NS & PT>OT $(*)$ & $\begin{array}{l}\text { NT>OT }(*), \\
\text { PT>OT (**) }\end{array}$ \\
\hline $\begin{array}{l}\text { Perceived } \\
\begin{array}{l}\text { Importance of } \\
\text { Math and } \\
\text { Science }\end{array}\end{array}$ & PT>OT $(* *)$ & NS & NS & NS \\
\hline
\end{tabular}

Table 5 details the results regarding those variables for which there were statistically significant differences between the means. The table includes the time points at which the means of the three variables were statistically significant, and at what level, according to post hoc student ttests for difference of means.

\section{How Positive Transition Group Students Talk About Math and Science:}

Prompted by the difference in math and science confidence patterns of the three groups over their first two years of college, we mined our qualitative interview data for comments related to math and science in order to find out if the individuals in these groups spoke about math- and science-related experiences differently. Our analysis strategy was to code the transcripts from students in the Positive Transition Group and Other Transition Group for both predetermined and emerging themes, compare the selections, and adjust the coding scheme until the categories were stabilized and all the transcripts were coded. The names that appear in the following are not actual student names, but study pseudonyms used to protect students' identities. 
Qualitative results regarding the Positive Transition Group students' confidence and perceived importance of math and science were largely consistent with the quantitative results presented earlier: many students seemed confident and enthusiastic about math and science and rated highly their skills in these subjects. Several students expressed strong, lifelong enjoyment of math and science. Many of them seemed not only to have excelled relative to their peers for many years in these subjects, but also to have always experienced pleasure and excitement during their study of these topics and to have continued to enjoy these subjects at the college level.

In high school in senior year, I did a natural science major with a math focus because I just enjoyed math so much. And by doing that math focus I got a stable bound for math. And then coming here to college, when everybody warned me about the algebra, I liked it a lot -- I enjoyed the class and I did well in it. (Paige, $2^{\text {nd }}$ year)

In high school again, I took a lot of science courses... I think seven... So I did quite a bit. And I liked them all. I did very well in them all and I read science things for fun and do activities related to that so I know it's something I'm comfortable with. (Burke, $I^{\text {st }}$ year)

When explaining why she rated herself a "9" (on a scale from 1 to 10) in math skills, Vicki talked about having a special passion for math:

Well math's always my favorite -- I think I can say that all the memorable teachers I've had are all math teachers. Math aptitude tests and stuff like that. Math has always been what I enjoy and I think the things you enjoy are also the things that you tend to understand and think "wow, that's cool”. (Vicki, $1^{\text {st }}$ year)

Like Vicki, many students seemed to think that having an interest in math and science naturally helped them to excel in those subjects:

I've just kind of always been good at math from a very early age, so I just worked ahead in elementary school and just sort of worked at my own pace and I've always had a pretty strong interest in math and sciences. So I think that having an interest in those has helped me become better at them. (Colin, $1^{\text {st }}$ year) 
I've been always interested in math and so I've always had a good knack for these types of fields and they've always interested me so I guess I developed the more personal level [of interest]. I study harder for me to learn more about these fields. (Aaron, $I^{\text {st }}$ year)

They also talked about having very firm understandings of mathematical arguments, making connections between topics studied in different classes, and feeling as if their knowledge compounded on itself.

Even though it's kind of tricky I feel like when I study it I get it. It's not only 'Oh I can do the arithmetic' -- I actually get it. (Paige, $I^{\text {st }}$ year)

When I sit in the lectures and I understand I like the way that everything fits together. This theory that I learned last year comes back and you can use it to prove that this one works too and everything just builds of each other. Just this language, it all fits together -- I like the way that it all fits together and I understand -- I feel like I understand how it all works. (Vicki, $2^{\text {nd }}$ year)

Students had also received affirmation from the adults in their lives recognizing their unique skills in math: "My mom's always told me that math was my thing since I was born." (Vicki, $2^{\text {nd }}$ year) Most said that they developed their skills primarily in classes throughout their lives, however some had received special recognition for their achievements in these subjects or had participated in activities outside of the classroom that helped them develop their skills.

I am much better in physics compared to chemistry so usually math is my best, second best is [physics]. And in Singapore in my school I was usually the top 1 or 2 in physics and I also took the Olympiad in Singapore -- I got a silver medal. And I was training to [do] all that. I think I was top 12 in Singapore in physics. (Luke, $1^{\text {st }}$ year)

I've taken a lot of science courses in both high school and college, and so I feel confident from having experience in those courses. Also from jobs or summer programs. I worked in a lab at [Institution], in a plant biology lab. And I'm working in a lab now in the Med. School Research Center. And summer programs -- I did a summer science and math program in high school. (Burke, $2^{\text {nd }}$ year) 
Enthusiasm for math was not universal; some of the feelings of the Positive Transition students towards the subject were more lukewarm. However even students who were not as confident in their math skills seemed to enjoy the subject:

Well I've enjoyed math and I don't really mind it. And it's pretty interesting, lots of things are interesting. But I didn't give myself a higher rating just because I don't necessarily have a knack for it. But I like it. (Burke, $2^{\text {nd }}$ year)

Many students seemed to think that math and science skills were very important for engineers. In response to the question, "Are there particular skills you feel are important for engineers to have?" many students cited math and science skills as among the most important. Vicki provided an answer typical of responses to this question:

Well, I guess you should be good at math and science, have aptitude in those areas, you should be creative and be able to brainstorm different solutions to a problem. (Vicki, $2^{\text {nd }}$ year)

Some were yet more firm in their emphasis on the centrality of math and science to engineering: [Engineering is] the application of scientific knowledge so of course the very first thing is you have to have good scientific knowledge background. And second is you have to know to apply it. (Luke, $1^{\text {st }}$ year)

Our qualitative inquiry into students' math and science confidence and perceived importance of math and science to engineering work yielded results that were generally consistent with our quantitative findings demonstrating that students in the Positive Transition Group were highly confident in these subjects and often felt that skills in these areas were very important to engineers.

\section{How Other Transition Group Students Talk About Math and Science:}

Other Transition students - those who become less confident in their math and science skills, or less psychologically motivated to study engineering between their freshman and sophomore years - seemed to have had somewhat different experiences with math and science than those of the Positive Transition students. As a group they seemed to be less enthusiastic towards math 
and science than Positive Transition students, though their individual attitudes varied from fairly positive, "I enjoy most of the science -- not all -- most of the science classes that I take, so I'm really motivated to try to do well," (Zora, $2^{\text {nd }}$ year), to lacking interest,

It's not like I didn't come from an engineering background or didn't have a strong math or science background. But when I came here I couldn't concentrate for [one] reason or the other on [foundational math course]. (Will, $2^{\text {nd }}$ year)

to a more negative attitude towards math and/or science,

It's hard to say whether I dislike math or not because I haven't taken any really high level math classes here so far. I'm afraid now that's one of the parts of engineering that I feel like I have less competence in. And I feel like I may dislike it because I may not have the ability to be as creative as I need to be to solve the problems. Back in high school I was good at the type of math where the book tells you, 'You see this type of problem, you do this formula.' And I could do that. But as things seemed to get more and more abstract I had more difficulty with it. And of course something can be frustrating if you're not good at it. (Felix, $1^{\text {st }}$ year)

Zora expressed mild apprehension about taking upper-level math and science courses:

I have had quite a few science classes but some are easier than the others. I find physics very hard and biology I find generally easier -- it's more memorization. I've had exposure to these areas but I don't feel like I've mastered them completely because I haven't taken college-level courses in them. (Zora, $1^{\text {st }}$ year)

I did well in math in high school but I know math in high school is definitely not the same as upper division math. (Zora, $2^{\text {nd }}$ year)

Matt felt like he lacked the preparation his peers had in math and science:

My soon-to-be roommate is just an absolute genius and I've come to know that a lot of people here just learned higher levels of math than I did, so it's not necessarily that they know [more] inherently. It's just that they've been taught more math than I have...my high school experience was particularly bad in the sciences. Freshmen year, I had a 
teacher that was fired after the first year. Sophomore year, I had a decent teacher, that was my best year in sciences I think. Junior year I had three different teachers for my science course. One took another job and one got fired. And then senior year I did independent study and I had senioritis, and that was a problem. (Matt, $1^{\text {st }}$ year)

Albert also felt like he lacked preparation in math, and this led to a particularly difficult and discouraging quarter in a foundational math course:

I had no calculus background going into the class, but the rest of the class did. As a result, the professor thought "Oh I can glance over things," which forced me to go over them a couple times. This caused a really stressful quarter, and made me feel very unconfident that I was going to pull it out, but I eventually did... it was a very tense two or three days until the grades came out. (Albert, $1^{\text {st }}$ year)

Matt seemed to like math less than he used to, but didn't elaborate

Math is my favorite subject. Well, in high school, I should say, it was my favorite subject. It's kind of still my favorite subject, but I'm not gonna be a math major. (Matt, $2^{\text {nd }}$ year)

He cited poor preparation to explain his lack of interest in science.

I haven't done very well in science classes. It's weird because a lot of science is related to math, but it just doesn't interest me in the same way that math does, and I think that as a consequence I don't try as hard. Part of it is I didn't really have a solid base in high school in science. (Matt, $2^{\text {nd }}$ year)

Several students made comments similar in spirit to Felix's, below. They appeared to be losing enthusiasm for math and science due in part to experiencing more difficulty with the material in college than they did in high school, and in part because they perceived that their peers were doing much better than they were. When asked to rate his confidence in math on a scale from 0 to 10 , Felix explained his decision to rank himself a '4' his 2nd year (down from ' 6 ' his 1 st year) as follows

In high school I thought I was pretty good at math because I was ahead. I even took calculus in freshmen year of high school. I didn't take much more than that, but I was 
ready for [foundational math course]. Here at [Institution] I realized that math in college is a totally different thing from math in high school. Even though I worked pretty hard at [foundational math course] I still got a B and that's a class in which probably only about 10-15\% of the class gets lower than a B-. So that didn't make me feel too good about my math ability. Since then I learned that a lot of math is about proofs and things that I didn't do in high school and that I'm not very good at... that's why I rated myself a 4. (Felix, $2^{\text {nd }}$ year)

These quotes suggest that Other Transition students have less enthusiasm for math and science than Positive Transition students. However, like Positive Transition students, they seem to have enjoyed these subjects in the past and had completed advanced coursework in them. Other Transition students talked about various factors in relation to their waning interest, including perceived lower competence and poor preparation relative to their peers and in general, struggling with the material, unpleasant experiences in foundational courses, and an increasing interest in other topics.

\section{DiscuSSION AND CONCLUSIONS}

In this study we characterized undergraduate engineering students based on their responses to measures of intrinsic psychological motivation and professional and interpersonal confidence. We divided the study population into three groups (Positive Transition, No Transition, and Other Transition) based on changes in these scores in the first two years of college and identified a group of students who made reported increases in one or both variables.

We compared the groups in terms of demographics and academic and professional persistence and found that the students in the Positive Transition Group demonstrated significantly higher professional persistence than students in the other groups. This link between the intention to persist into the engineering profession and early increases in confidence and motivation suggests that initial positive experiences—students' "first impressions" of engineering majors—may have an important influence on long-term plans. We observed many similarities among the three groups in terms of study variables, but found differences in confidence in and perceived importance of math and science skills (with the PT group possessing the highest mean). 
PT students appeared to maintain high confidence in math and science skills over the first few years of college while NT students had lower but consistent confidence scores (though not statistically different from PT students), and OT student confidence in math and science dropped between their first and second years of college. PT students also maintained high perceived importance of math and science skills while NT students had lower perceived importance and the perceived importance of OT students started low and fluctuated.

In many engineering programs, students often take basic math and science classes in the first few years. These findings could indicate that early increases in confidence and motivation are associated with experiences in these foundational classes. It was interesting to observe that OT students had a lower perceived importance of math and science at the first time point which could be linked to their drop in confidence at later time points. In a future study, it would be interesting to compare these confidence and perceived importance scores with actual performance measures in foundational math and science classes.

Student interviews from the same time period yielded results largely consistent with quantitative findings regarding math and science skills: we found evidence that PT students enjoyed and were confident in math and science and felt that these skills were important for engineering. OT students, however, seemed to have less enthusiasm for math and science. Though they described high school experiences similar to PT students'-having completed advanced coursework and liking the subject-several mentioned having had a hard time in foundational math courses, feeling ill-prepared, and feeling like they were less competent in these subjects than their peers. Recalling that PT students had the highest professional persistence in engineering and OT students the lowest, this could mean that preparation and foundational coursework in engineering programs has a larger influence on long-term persistence than previously thought.

It would be valuable to apply the Quadrant Analysis approach to data from a larger population. A study comparing data from students at different universities could provide additional insights into whether the connections among increases in confidence and motivation in the first few years of college and high confidence and perceived importance of math and science skills are trends specific to this university or can be generalized to a broader population. It would also be enlightening to apply the Quadrant Analysis over more time points. The data available for this 
study constrained the time period over which the analysis could be performed, but a future study could investigate whether the trends observed here continue into the later years of college.

\section{ACKNOWLEDGEMENTS}

Support by the National Science Foundation under Grant No. ESI-0227558, which funds the Center for the Advancement of Engineering Education (CAEE) is acknowledged. We are also grateful for the many thought-provoking discussions we had with our Stanford colleagues (Micah Lande, Samantha Brunhaver, Sarah Parikh, George Toye, and Tiffany Tseng) on the Quadrant Analysis and interpreting our data.

\footnotetext{
'Sheppard, Sheri, Shannon Gilmartin, Helen Chen, Krista Donaldson, Gary Lichtenstein, Özgür Eris, Micah Lande, George Toye. (2010) (APPLES2): Exploring the Engineering Student Experience: Findings from the Academic Pathways of People Learning Engineering Survey (APPLES) [TR-09-02]. Technical report in preparation.

ii Shuman, Larry J., Mary Besterfield-Sacre and Jack McGourty. 2007. The ABET "Professional Skills" - Can They Be Taught? Can They Be Assessed? Journal of Engineering Education, January 2005, Vol 94 No 141 -55.

iii Association of American Colleges and Universities. (2008). College learning for the new global century. Retrieved January 4, 2010, from http://www.aacu.org/advocacy/leap/documents/GlobalCentury_ExecSum_final.pdf

iv Eris, Özgür, Debbie Chachra, Helen Chen, Camelia Rosca, Larry Ludlow, Sheri Sheppard, and Krista Donaldson. 2007. A Preliminary Analysis of Correlates of Engineering Persistence: Results from a Longitudinal Study. In Proceedings of the American Society for Engineering Education Annual Conference, Honolulu, Hawaii, June 24-27, 2007.

${ }^{\vee}$ Ryan, Richard M. and Edward L. Deci. 2000. Intrinsic and Extrinsic Motivations: Classic Definitions and New Directions. Contemporary Educational Psychology: 25, pp. 54-67.

${ }^{v i}$ Guay, F., Vallerand, R.J., \& Blanchard. C. (2000). On the assessment of situational intrinsic and extrinsic motivation: The Situational Motivation Scale (SIMS). Motivation and Emotion, 24(3), 175-213.

vii Seymour, E., and Hewitt, N.M. (1997). Talking about leaving: Why undergraduates leave the sciences. Boulder, CO: Westview Press.

viii Eris, Özgür, Debbie Chachra, Helen Chen, Sheri Sheppard, Larry Ludlow, Camelia Rosca, Tori Bailey, and George Toye. 2009. Outcomes of a Longitudinal Administration of the Persistence in Engineering Survey. Manuscript in press.
} 